\title{
An overview of urinary proteomics applications in human diseases
}

This article was published in the following Dove Press journal:

International Journal of High Throughput Screening

17 November 2010

Number of times this article has been viewed

\author{
Gayathri Gopalan' \\ Veena S Rao' \\ Vijay V Kakkar² \\ 'Tata Proteomics and Coagulation \\ Unit, Thrombosis Research \\ Institute, Bangalore, India; \\ ${ }^{2}$ Thrombosis Research Institute, \\ London, United Kingdom
}

\begin{abstract}
A major challenge in clinical proteomics is the identification of reliable biomarkers that help early diagnosis of disease, which will not only assist the clinician but also contribute to the development of personalized medicine. Urinary proteomic studies provide information on urine composition along with insight into renal physiology, kidney disease states, and other associated diseases. In the past decade, technical advances in the design of highly sensitive mass spectrometers and accurate protein quantitation technologies have led to the application of urinary proteomics in diverse research areas, including basic biomedical and clinical sciences. Of specific interest is the identification of biomarkers by virtue of improvements in instrumentation, bioinformatics, and database development. Here, we review recent discoveries in urinary proteomics with respect to identifying novel biomarker, its current challenges, and potential for future research.
\end{abstract}

Keywords: urinary proteomics, biomarker, mass spectrometry

\section{Introduction}

The word "proteomics" was coined by Marc Wilkins in 1994 and traces its roots to techniques such as two-dimensional gel electrophoresis (2DE) pioneered by O'Farrell and Klose ${ }^{1-3}$ Proteomics elucidates the proteome and can help identify clinically relevant biomarkers in cell types (eg, epithelial, mesangial, endothelial), tissues (eg, renal cortex), or specific parts of a tissue (eg, glomerulus), thus assisting in diagnosis and disease staging. Proteomic analyses have also enabled the de novo establishment of protein patterns using mass spectrometers, soft ionization techniques, and software tools. Thus, compared to conventional methods of biomarker identification, proteomics detects diagnostic protein signatures with increased sensitivity, enabling the invention of diagnostic tests for the clinic and noninvasive ways of monitoring disease and treatment. Two sources of sample material are routinely used in proteomic studies: body fluids (eg, urine, blood) and tissue. Urine is used more often due to its stability, resistance to proteolytic degradation, low background noise, and noninvasive sample collection method. In this review, we focus on work that has been reported for novel urinary biomarkers and current standing of urinary proteomics in prognosis and diagnosis of disease.

\section{Use of urine for proteomic analyses and urinary biomarkers}

Urine is produced by the kidney and allows the human body to eliminate waste products from blood. Many proteins and peptides can be identified in normal human urine, which come from various sources including filtration of plasma proteins; impaired 
reabsorption of filtered proteins; injured glomeruli, tubules, infiltrating inflammatory cells, or connective tissue; and proteins entering urine in the urinary tract below the kidney. Of the urinary proteins excreted, $48 \%$ are in sediments, $49 \%$ soluble, and the remaining 3\% are in exosomes. ${ }^{4-6}$ Thus, urine contains information not only from the kidney and the urinary tract but also from other organs, and urinary proteome analysis may allow identification of biomarkers for both urogenital and systemic diseases. Urine protein profiling has resulted in the identification of 124 proteins in 2001 and approximately 1,500 proteins in 2006 . $^{7,8}$ Capillary electrophoresis coupled to mass spectrometry (CE-MS) has detected several thousand urine peptides, including a variety of clinical conditions such as urogenital disorders ${ }^{9}$ (reviewed in Ref. 9) on a platform designed for clinical peptidomic assessments. Now it is determined that the human urinary proteome contains over 100,000 different peptides and at least 5,000 occur with high frequency. ${ }^{9}$ Thus, urinary proteomic analysis is well-suited to identify predictive biomarkers and dissect pathogenic mechanisms underlying chronic renal diseases. Recently, there has been growing interest in the human urine proteome as it yields information on renal physiology and pathophysiology, kidney dysfunction, novel proteins associated with pathogenic states in cancers, and cardiovascular, autoimmune, infectious, and systemic diseases. ${ }^{10}$ For example, urinary proteomic analyses have been used to identify disease markers for the kidney and urogenital tract and for distal organs such as the brain and intestine. ${ }^{11,12}$ Despite these benefits, one of the main disadvantages of using urine is the variation in protein and peptide concentrations as a result of changes in daily fluid intake. This shortcoming can be overcome by normalization with creatinine or other peptides routinely present in urine. ${ }^{13,14}$ Biomarkers offer an attractive option for noninvasive diagnosis and prognosis of disease as they deviate significantly from average in correspondence with health conditions. They can be used for disease detection and classification, choosing therapeutic agents, assessing prognosis, and monitoring therapeutic regimens. Urinary biomarkers have long been used to diagnose diseases such as urinary tract cancers and other malignancies, eg, fibrinopeptide A. ${ }^{15}$ Recently, basic considerations for using proteomics in nephrology and discovery of protein biomarkers for kidney diseases were summarized. ${ }^{16-18}$

\section{Techniques for urinary proteomic studies}

Numerous techniques have been developed for protein separation, purification, and identification each with its own merits and demerits. The urine dipstick test - screening test for proteinuria - has low sensitivity (approximately $250 \mathrm{mg} / \mathrm{L}$ ) and fails to detect microalbuminuria. ${ }^{19}$ Precipitation techniques detect all urinary proteins with a sensitivity of $2.5 \mathrm{mg} / \mathrm{L}$, but are rarely used due to interference from exogenous compounds. ${ }^{20}$ The protein-creatinine ratio shows reliable results with urine samples obtained from a 24-hour collection and is a test that is now routinely used in clinical practice. $^{21}$

Studies in urinary proteomics involve a combination of protein concentration techniques, separation methods, and mass spectrometry (MS) (Figure 1). Sample preparation procedures such as ultrafiltration, centrifugation, reverse phase separation, dialysis, lyophilization, affinity column or beads, and precipitation using organic solvents have been used to concentrate and desalt urinary proteins to enhance sensitivity, dynamic range, and increase efficiency of protein identification. Gel-based technique or liquid chromatography (LC)-based technique are used to understand the pathophysiology and disease mechanism, while proteomic profiling that differentiates between affected vs healthy individuals employs surface enhanced laser desorption/ ionization (SELDI) technology, CE-MS, and microarray and microfluidic technology on chip. Biomarker discovery and validation for diagnosis and prognosis of diseases has been achieved by the latter approach. Recent advances in MS instrumentation and proteomic methods have fueled great progress in the field. In the following, we will briefly discuss conventional and MS-based techniques outlining their advantages and limitations (Table 1).

\section{D polyacrylamide gel electrophoresis}

$2 \mathrm{D}$ polyacrylamide gel electrophoresis (2D PAGE) is the most widely used method for protein separation in urinary proteomics. $^{2,22}$ In the first dimension, proteins or polypeptides are separated on the basis of their net charges by isoelectric focusing, and in the second dimension, they are separated on the basis of their molecular masses by electrophoresis. Because it is unlikely that two molecules will be similar in both properties, molecules are more effectively separated in $2 \mathrm{D}$ electrophoresis than in $1 \mathrm{D}$ electrophoresis. On separation, the proteins are stained and the spots are analyzed using immune detection or MS..$^{23,24}$

\section{D difference gel electrophoresis}

Two-dimensional difference gel electrophoresis (2D DIGE) reduces gel-to-gel variability, facilitating easy and accurate quantitative sample-to-sample comparisons of spots. In 2D 


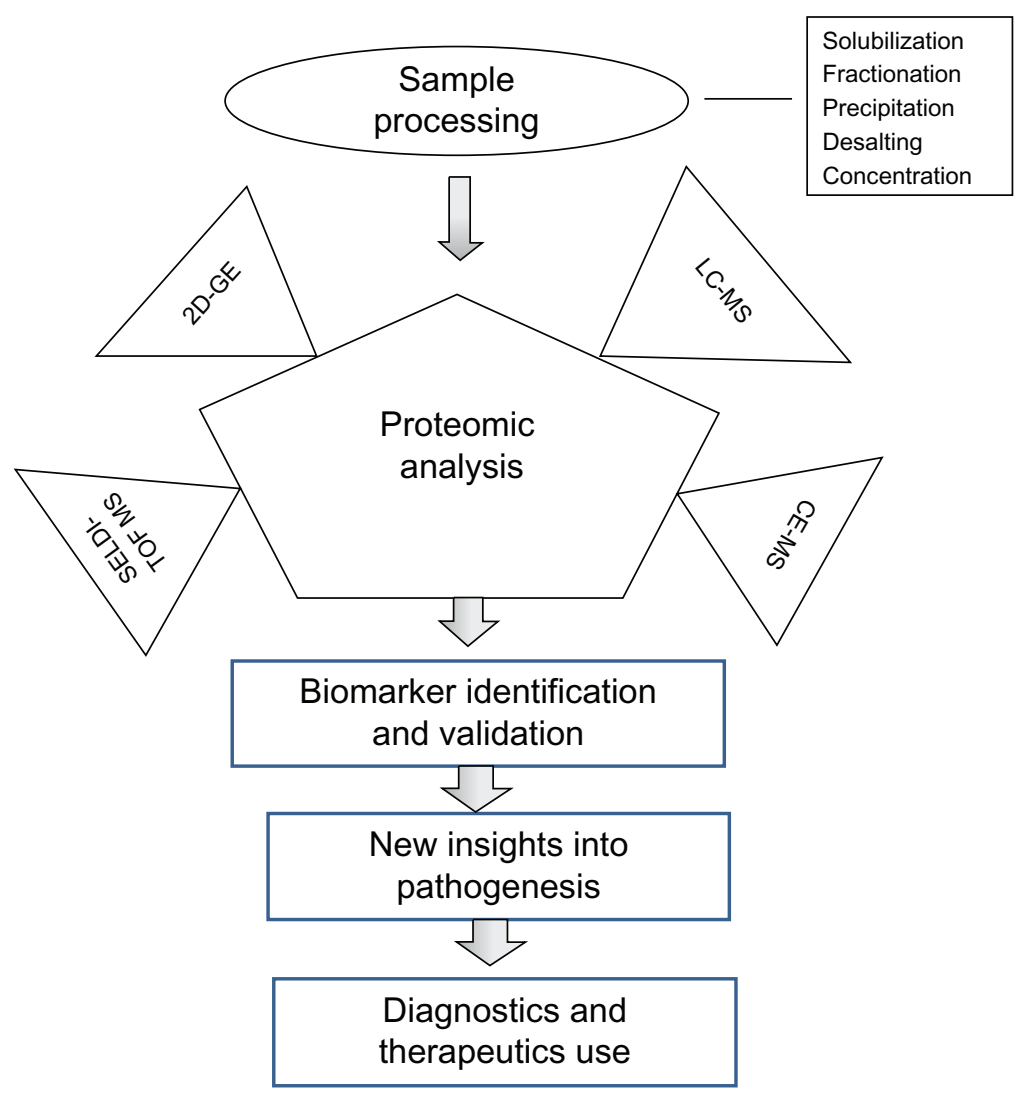

Figure I Overview of different proteomic methodologies.

Abbreviations: 2D-GE, two-dimensional polyacrylamide gel electrophoresis; LC-MS, liquid chromatography coupled to tandem mass spectrometry; SELDI-TOF MS, surface-enhanced laser desorption/ionization time-of-flight mass spectrometry; CE-MS, capillary electrophoresis coupled to mass spectrometry.

DIGE, the protein samples are labeled with fluorescent dyes and then separated by 2D-PAGE. Different protein samples are labeled with different fluorescent dyes - Cy3 and Cy5and are resolved in a single $2 \mathrm{D}$ gel to compare the relative quantity of specific proteins. The gels are scanned by laser scanners and the image of 2D-PAGE is obtained from single gels. Gel-to-gel variations are the most severe problem in the gel-based proteomics. However, 2D DIGE solves this problem by resolving the multiple samples in single gels. The different samples, as many as the number of fluorescent dyes, can be studied in single gels. However, this method is time-consuming and applicable to proteins ranging from 10 to $200 \mathrm{kDa}$ and cannot be used for highly hydrophobic proteins. $^{25,26}$

\section{Mass spectrometry}

MS is a widely used analytical technique that measures the mass-to-charge ratio of ions. On the basis of the ionization process of analytes (biological samples), there are 2 types of mass spectrometers: matrix assisted laser desorption/ ionization (MALDI) MS and electrospray ionization (ESI) MS. MALDI coupled with time-of-flight (TOF) analyzer measures the mass of intact proteins and peptides generating singly charged ions, which helps spectra interpretation. However, MALDI is more susceptible to signal suppression. ${ }^{27}$ ESI is generally coupled with ion traps and quadruple instruments and used to generate fragment ion spectra of selected precursor ions that are multiply charged requiring sophisticated software for data analysis. LC provides a powerful fractionation method compatible with MS that separates large amounts of analytes on a LC column with high sensitivity. One dimensional and 2D chromatographic approach has been used in recent studies for protein identification. ${ }^{28-30}$ Multidimensional protein identification technology - first introduced by Yates et al - uses separation by cation-exchange and reversed-phase LC before MS/MS detection. ${ }^{31}$ Castagna et $\mathrm{al}^{32}$ exploited beads coated with a hexametric peptide ligand library for urinary protein concentration and equalization and identified 383 unique gene products by LC-MS/MS using a linear ion trap-Fourier transform instrument In spite of being multidimensional and highly sensitive, LC-MS has several disadvantages: 1) sample digested in trypsin resulting in high complexity, 2) time-consuming, and 3) very sensitive to interfering compounds. 
Table I Comparison of different proteomic analysis techniques for biomarker discovery in clinical applications

\begin{tabular}{|c|c|c|}
\hline Technique & Advantages & Limitations \\
\hline $2 \mathrm{DE}$ & $\begin{array}{l}\text { Widely available, directly identify proteins of different } \\
\text { abundance, separation of charge forms reflects post- } \\
\text { translational modifications, applicable to large molecules, } \\
\text { enables estimation of actual molecular weight of } \\
\text { large molecules, sequencing of biomarkers easy to perform }\end{array}$ & $\begin{array}{l}\text { Not applicable to molecules }<10 \mathrm{kDa} \text {, no automation, } \\
\text { labor intensive, dynamic range, difficult to detect } \\
\text { low abundance and hydrophobic protein, medium } \\
\text { throughput, moderate compatibility }\end{array}$ \\
\hline LC-MS & $\begin{array}{l}\text { Automation, high sensitivity and more likely to } \\
\text { detect low abundance and hydrophobic proteins, } \\
\text { multidimensional, sequencing by MS/MS }\end{array}$ & $\begin{array}{l}\text { Time-consuming, quantification and measurement of } \\
\text { post-translational modifications require additional } \\
\text { tools, sensitive towards interfering compounds, } \\
\text { medium throughput, restricted mass range }\end{array}$ \\
\hline CE-MS & $\begin{array}{l}\text { Reproducible, high sensitivity, low sample volume, } \\
\text { multidimensional low cost, any MS/MS sequencing } \\
\text { possible, appears to be a good technique for } \\
\text { biomarker discovery }\end{array}$ & $\begin{array}{l}\text { Not suited for larger molecules }(>20 \mathrm{kDa}) \text {, proteins } \\
\text { not identified without additional steps }\end{array}$ \\
\hline MALDI MS & $\begin{array}{l}\text { Sensitive for low molecular weight proteins, can be } \\
\text { coupled with different analytical techniques }\end{array}$ & $\begin{array}{l}\text { Restricted sensitivity for larger polypeptides, proteins } \\
\text { not identified }\end{array}$ \\
\hline SELDI MS & $\begin{array}{l}\text { User friendly, high throughput, and sensitivity, low } \\
\text { sample volume, TOF/TOF sequencing possible, many } \\
\text { options for resolution, samples can be enriched } \\
\text { for specific low abundance }\end{array}$ & $\begin{array}{l}\text { Low resolution, restricted to selected peptides, } \\
\text { lack of comparability, sensitive towards interfering } \\
\text { compounds, not intrinsically quantitative, lack of } \\
\text { protein identification }\end{array}$ \\
\hline Protein-binding arrays & $\begin{array}{l}\text { Sensitive, rapid, samples can be compared with } \\
\text { fluorescent labels }\end{array}$ & $\begin{array}{l}\text { Does not detect proteins that do not bind to it, } \\
\text { specificity is variable }\end{array}$ \\
\hline
\end{tabular}

Abbreviations: 2DE, two-dimensional gel electrophoresis; MS, mass spectrometry; LC-MS, liquid chromatography coupled to tandem MS; CE-MS, capillary electrophoresis coupled to MS; MALDI MS, matrix assisted laser desorption/ionization coupled to MS; SELDI MS, surface-enhanced laser desorption/ionization coupled to MS; TOF, timeof-flight.

CE-MS is based on separation of analytes through a liquid filled capillary column in an electric field (300-500 V/cm) coupled to ESI MS. CE-MS offers a great tool for urinary proteomic studies with its high sensitivity, speed, low sample volume, and multidimensional and low cost analysis. A disadvantage of $\mathrm{CE}$ is that it is not suitable for the analysis of high molecular weight proteins $(>20 \mathrm{kDa})$. However, the urinary proteome of healthy individuals mostly contain low molecular weight proteins; in such cases, the restricted ability to analyze large native proteins does not constitute a severe drawback. ${ }^{33,34}$ The different CE modes that can be applied toward proteomic analyses have recently been described. ${ }^{35,36}$ Sequencing of potential protein biomarkers defined by CE-MS analysis can be achieved by directly interfacing CE with MS/MS instruments or targeted sequencing using LC-MS/MS. Consequently, CE-MS has emerged as an attractive option in proteomic technology and was introduced for diagnostic testing with success.

The recent SELDI technology selectively binds a subset of proteins and peptides directly on the MALDI target, reducing sample complexity and requires a small sample volume $<10 \mu \mathrm{L}$. This technology uses protein-chip arrays consisting of $10 \times 80-\mathrm{mm}^{2}$ aluminum strips with eight $2 \mathrm{~mm}$ spots coupled to a mass spectrometer that detects the proteins. ${ }^{37,38}$ The solid-phase chromatographic surface of the chip can be activated either chemically or biochemically.
Different methods of profiling urinary proteins have been described using SELDI-MS. Despite the ease of use of this technique, the disadvantage lies in difficulties with calibration, lack of precision of the determined molecular masses of the analytes, restriction on information to proteins binding on the chip surface, and reproducibility of defined biomarkers.

Protein arrays and non-MS approaches can also be used to detect specific proteins. Protein microarrays generally fall into three categories: function microarrays, analytical microarrays, and reverse phase microarrays. ${ }^{39}$ High-throughput profiling and discovery of low molecular weight markers make them an ideal approach for urinary proteomics. However, microarrays need a specific probe for each protein analyzed, have low density coverage allowing detection of only a few proteins, and they cannot detect post-translational modifications.

\section{Application of urinary proteomics in renal diseases}

Proteomics of kidney and urine provides an important tool for understanding issues in renal physiology and pathophysiology. A case in point is immunoglobulin A nephropathy (IgAN), the most common form of immune complex-mediated glomerulonephritis that has no noninvasive marker available for the diagnosis to date. ${ }^{40}$ One of the first reports was the analysis of urinary polypeptide markers of membranous glomerulonephritis by SELDI and CE-MS indicating that 
the stable level of urinary $\alpha-1$-microglobulin might serve as the IgAN-specific biomarker. ${ }^{41}$ Further, Rocchetti et $\mathrm{al}^{42}$ confirmed that low levels of urinary kininogen could serve as a marker for prediction of the poor response of IgAN to the ACEI therapy.

In addition to disease-specific biomarkers, stage-specific urinary markers can be defined, eg, urinary markers of diabetic nephropathy (DN). DN is the main cause of morbidity and mortality in patients with type 1 diabetes mellitus, and microalbuminuria has been established as a good marker for tracking development and progression of diabetic renal disease. ${ }^{43}$ But immunounreactive forms of albumin are not detected by the conventional method. Meier et al used CE-MS to identify urinary polypeptides and proteins and subsequently validated biomarkers for diabetes and DN along with biomarkers that differentiated between DN and other chronic renal diseases. ${ }^{44,45}$ Sharma et al adopted 2D DIGE to evaluate the urinary proteome of diabetics and identified $\alpha$-1-antitrypsin as an unregulated peptide, later confirmed by immunoassay. Proteomic profiling of urine sample of type 2 diabetics patients (microalbuminuria with normoalbuminuria) identified UbA52, an ubiquitin ribosomal fusion protein exclusively excreted by diabetic patients with proteinuria. $^{46,47}$

Identification of markers for evaluation of kidney transplant-associated complications is one of the important areas of research in urinary proteomics. Acute rejection is a main factor that determines long-term graft function and survival in renal transplant patients and has been an important target for investigations. CE-MS was used on urinary samples from patients with different grades of subclinical or clinical acute transplant rejection, patients with urinary tract infection, and patients without evidence of rejection or infection. ${ }^{37,48}$ Substantial differences were found between patients with transplanted kidneys and patients with native kidneys, most likely due to treatment with cyclosporin A, a calcineurin inhibitor immunosuppressant. Additional biomarkers were identified that allowed differentiation between infection and acute rejection. CE-MS of urine samples from patients with grades of subclinical or clinical acute transplant rejection, urinary tract infection, and patients without evidence of rejection or infection was performed. SELDI-TOF MS analysis followed by tandem MS and ProteinChip immunoassay identified 1-defensin and antichymotrypsin as valuable candidate biomarkers of acute rejection. ${ }^{49}$

Chronic allograft nephropathy is the most common cause of late renal allograft failure clinically characterized by a slow deterioration of renal function. Studies show that chronic renal allograft lesions progress between the 4th and 14th month, while serum creatinine, calculated GFR, and arterial pressure remain stable. The histopathologic hallmarks of these patients are chronic interstitial fibrosis, tubular atrophy, vascular occlusive changes, and glomerulosclerosis. In addition to elevated serum creatinine - usually associated with proteinuria and arterial hypertension - more specific and sensitive markers are needed to identify high-risk patients or initial lesions without any changes in serum creatinine or proteinuria. In a recent study, Quintana et al established a pattern for histologic lesions associated with distinct graft outcomes and found 14 protein ions that best discriminated between interstitial fibrosis and tubular atrophy and patients with chronic active antibody-mediated rejection. ${ }^{50}$

Acute kidney injury or acute renal failure remains a significant problem in critically ill patients and is typically diagnosed by measuring serum creatinine. Unfortunately, creatinine is an unreliable indicator during acute changes in kidney function. ${ }^{51,52}$ Lefler et al utilized 2DE MALDITOF-MS and identified several proteins - including albumin, apolipoprotein A-IV, $\beta$-2-microglobulin, lithostathine, mannose-binding lectin-associated serine protease 2-associated protein, plasma retinol-binding protein, transferrin, transthyretin, vitamin D-binding protein, and Zn $\alpha-2$ glycoprotein - in the effluent by peptide mass fingerprinting. ${ }^{53}$ The identification of biomarker panels in urine (NGAL, KIM-1, IL-18, cystatin C, $\alpha$-1-microglobulin, fetuin-A, Gro- $\alpha$, and meprin) will be important in future studies to validate the sensitivity and specificity of these biomarker panels in clinical samples from large cohorts and multiple clinical situations. ${ }^{54,55}$

\section{Application of urinary proteomics in cancer}

Urinary proteomics offers an attractive approach for cancer biomarker discovery in kidney and urological malignancies and systemic malignancies. ${ }^{56-60}$ Prostate cancer (PCa) - a commonly diagnosed cancer in men - relies only on a digital rectal examination with a serum prostate-specific antigen test. In a pilot study, CE-MS techniques defined potential urinary markers of PCa ${ }^{61}$ The PCa biomarkers were identified with $92 \%$ sensitivity and $96 \%$ specificity upon cross-validation. Using urine samples from $54 \mathrm{PCa}$ and 62 benign prostatic hyperplasia (BPH) patients and a model with 10 potential biomarkers resulted in the prediction of $88.9 \%(32 / 36)$ of the $\mathrm{PCa}$ and of $66.7 \%$ (16/24) of the BPH patients in a second blinded set of patient samples. ${ }^{62}$ Inclusion of age and free prostatespecific antigen increased the sensitivity and specificity 
to $91 \%$ and $69 \%$, respectively. Rogers et al ${ }^{56}$ analyzed the urinary proteome in patients with clear cell renal carcinoma and compared it to healthy volunteers and patients with other urogenital diseases using the CE-MS technique and identified fibrinopeptide $\mathrm{A}$ as a proven biomarker for ovarian and gastric cancer from a pattern of 22 polypeptide masses. One of the first studies using 2D DIGE for the analysis of the urinary proteome aimed to identify biomarkers for bladder cancer and identified 12 differentially expressed spots. ${ }^{63}$ One of the differentially expressed proteins identified with a specificity and sensitivity of $81.3 \%$ and $81.3 \%$, respectively, was regenerating protein- 1 . Vlahou et $\mathrm{al}^{64}$ identified defensin as a urothelial (transitional cell) carcinoma (TCC) biomarker by analyzing urine samples $(\mathrm{N}=94)$ from patients with $\mathrm{TCC}$, patients with other urogenital diseases, and healthy donors. Theodorescu et $\mathrm{al}^{15}$ described the CE-MS detection and validation of biomarkers of urothelial carcinoma. In a blinded assessment, the prediction model based on 22 polypeptides correctly classified all patients with urothelial carcinoma and healthy volunteers (100\% sensitivity and specificity). In first ever proteomic analysis of bladder cancer cell exosomes, Welton et $\mathrm{al}^{65}$ reported 353 proteins with 72 proteins not being previously identified. Some of the biomarkers, basigin, galectin-3, and 5T4, were validated using western blotting and flow cytometry.

\section{Application of urinary proteomics in nonrenal diseases}

While the main focus of urinary peptidomic analysis was biomarker definition for renal and urological diseases initially, the scope of research has broadened in recent years to include nonrenal diseases. Urinary proteomics can be applied to non-kidney diseases, particularly those with marked changes in circulating levels of medium molecular weight proteins passing through the glomerular barrier. Studies showing the identification and validation of urinary markers for nonurinogenital diseases are emerging.

CE-MS was used for the clinical follow-up of patients after allogeneic hematopoietic stem cell transplantation (HSCT). ${ }^{66}$ In a pilot study, urine samples from $40 \mathrm{HSCT}$ patients and 5 patients with sepsis were collected over a 100 -day period with a maximum of 10 samples per patient. A pattern of 16 differentially excreted polypeptides indicated early graft-vs-host-disease. A model of 31 candidate biomarkers allowed accurate classification of urine samples in the training set with a sensitivity of $100 \%$ and specificity of $98 \%$. Recent reports have identified urinary biomarkers predictive of obstructive sleep apnea, early ovarian cancer, and nonsmall-cell lung cancer. ${ }^{67-69}$ It is likely that urine testing will be used in the future to screen for more systemic disorders, with no or limited renal involvement.

\section{Urinary proteomics and cardiovascular disease}

Annually, cardiovascular disease claims over 10 million lives worldwide. Despite multiple clinical, electrographic, and biochemical characteristics, there are subgroups of patients who progress to life-threatening coronary artery disease (CAD) without overt symptoms. Early diagnosis would allow for life-saving treatment decisions to be made in a safe and cost-effective manner, reducing aggressive therapy regimens and nonessential invasive procedures.

Proteomic analysis of urine could yield biomarkers for the diagnosis and monitoring of CAD. Using CE on-line coupled to ESI-TOF MS, Zimmerli et al ${ }^{70}$ examined urine from 88 CAD patients and 282 controls. Multiple biomarker patterns were found to distinguish healthy controls from CAD patients, and 15 peptides were extracted to define a CAD signature panel (Table 2). Five polypeptides constituting the CAD-specific panel were identified as collagen type I/ type III fragments, major components of arterial walls. All sequenced collagen fragments were upregulated in CAD samples compared with controls, suggesting elevated collagen degradation levels. In line with these data, increased circulating levels of collagenases - such as MMP-9 - have been reported in patients with stable angiographic coronary atherosclerosis or intermittent claudication. ${ }^{71-73}$ In addition to the collagen fragments, a membrane-associated progesterone receptor component 1 fragment that associates with thoracic ascending aorta, internal carotid artery, coronary artery, and left atrial appendage was identified. ${ }^{74}$ In a blinded assessment, these urinary biomarkers identified CAD patients with $>90 \%$ sensitivity and specificity. Diagnosis of CAD by urinary proteome analysis was further evaluated for its prognostic potential.

In recent studies, von Zur Muhlen et al investigated the ability of urine and plasma polypeptide patterns to predict CAD in 67 patients with new-onset or stable angina. ${ }^{75}$ Polypeptide patterns associated with CAD were identified and confirmed by histology studies as peptides are derived from collagens of human atherosclerotic plaques. They found that a combination of 17 polypeptides could predict CAD with a sensitivity of $81 \%$, specificity of $92 \%$, and accuracy of $84 \%$. By contrast, no polypeptide sequence in plasma had sufficient power to discriminate between CAD and non-CAD patients. Remarkably, 84 biomarkers identified 
Table 2 Application of urinary biomarkers for various diseases

\begin{tabular}{|c|c|c|}
\hline Disease & Biomarker & Current status \\
\hline Renal transplantation & $\begin{array}{l}\text { Interleukin-18, neutrophil gelatinase-associated lipocalin } \\
\text { for graft function, } \beta \text {-2-microglobulin, } \beta \text {-defensin-I, } \\
\alpha \text {-I-antichymotrypsin for acute renal rejection }\end{array}$ & $\begin{array}{l}\text { Mass spectrometic studies have identified more } \\
\text { unidentifeid proteins, larger patient cohort studies } \\
\text { needed for good sensitivity and specificity to be } \\
\text { recommended for routine clinical use }\end{array}$ \\
\hline Acute kidney injury & $\begin{array}{l}\text { Exosomal fetuin A, cystatin C, interleukin- } 18 \text {, kidney injury } \\
\text { molecule I, sodium-hydrogen exchanger isoform 3, lipocalin }\end{array}$ & $\begin{array}{l}\text { Most studies are based on animal models, } \\
\text { translational studies to humans are needed }\end{array}$ \\
\hline Bladder cancer & $\begin{array}{l}\text { Nuclear matrix protein } 22 \text {, pro-u-plasminogen activator, } \\
\text { calreticulin, } \gamma \text {-synuclein, regenerating protein-I }\end{array}$ & $\begin{array}{l}\text { Studies needed in larger cohort to establish true } \\
\text { sensitivity and specificity }\end{array}$ \\
\hline Prostrate cancer & $\begin{array}{l}\text { Thymosin I } 5, \alpha \text {-methylacyl-coenzyme A racemose, prostatic } \\
\text { inhibin-like peptide }\end{array}$ & Multiple marker approach needed \\
\hline Cardiovascular disease & $\begin{array}{l}\text { Collagen } \alpha \text {-I chain (type I, III), membrane-associated } \\
\text { progesterone receptor component I }\end{array}$ & Larger cohort studies needed \\
\hline
\end{tabular}

by Zimmerli et al were confirmed in this study including fragments of collagen $\alpha-1$ (I and III). Together, these data strongly support that CAD shows specific polypeptide patterns in urine. A study by Snell-Burgeon et al validated urinary biomarkers for diabetes and two common complications, CAD and $\mathrm{DN} .{ }^{76} \mathrm{In}$ a prospective study using samples from the coronary artery calcification in type I diabetes, a versatile screening method was designed for concomitant diagnosis of early diabetic kidney disease and subclinical CAD. Using the CAD score, the cardiovascular event could be predicted in a cohort of 38 prospectively collected blinded samples with a $P$-value of 0.0016 that remained significant after adjusting for age, albumin excretion rate, systolic/ diastolic blood pressure, waist circumference, intra-abdominal fat, $\mathrm{HbA} 1 \mathrm{c}$ levels, and blood lipid profiles. Urinary proteome analysis using the online combination of $\mathrm{CE}$ and ESI-MS revealed patterns associated with the development of clinical CAD, even when adjusted for known CAD risk factors and potential confounders.

Research carried out for identification of cardiovascular biomarkers by urinary proteomics thus far has allowed the identification of CAD and non-CAD patients with high sensitivity, specificity, and accuracy. These highlight that noninvasive urine test for the detection of atherosclerotic disease - in particular CAD - may significantly help early diagnosis and treatment.

\section{Challenges and future perspectives}

Proteomics is a great tool to understand protein expression, post-translational modifications, and functions, which help to identify and classify affected from unaffected individuals in a clinical setting. Urinary proteomics is fast emerging as a powerful method for biomarker discovery, diagnostics, and prognostics not only for kidney disease but also for non kidney diseases. Proteomic techniques have greatly enhanced the understanding of kidney dysfunction along with other related diseases. ${ }^{26}$ Several candidate biomarkers have been identified but only a few has been validated. Thus, there is an urgent need for discovery, characterization, and validation of biomarkers to translate these results into clinical practice.

Major obstacles in urinary proteomics have been the lack of standards for the samples, processing, and analytical reproducibility. ${ }^{77}$ This has resulted in marked variability in the protocol followed and, as such, the results are not comparable. Need for standardization of sample protocol, viz, sample collection, study design, cohort size, controls, and establishment of database of mass spectrometric methodology have been addressed recently by "Human Kidney and Urine Proteome Project" (www.hkupp.org) and "European Network for Kidney and Urine Proteomics" (www.eurokup.com). ${ }^{78,79}$

Another major concern has been the lack of bioinformatics software for data normalization and evaluation. Earlier data are not comparable due to different analysis approaches followed. ${ }^{80}$ These issues clearly underline the need for a specific format for computational interpretation of the resulting mass spectra, which will yield information more likely to be specific and clinically informative.

In the future, a combination of proteomics and functional genomics in routine clinical practice will help with basic/ fundamental investigations of disease. Advances in sample processing, fractionation, and analysis will lead to a better understanding of low-abundance proteins known to play a significant role in disease.

\section{Conclusion}

This review concentrated on urinary proteomics as an approach with applications in human diseases. Urinary protein profiling is turning out to be a viable platform for better understanding disease pathology in clinical proteomics. Urinary proteomics has undergone many advances resulting 
in the identification of novel proteins and candidate disease biomarkers, but the progress has been slow. Many challenges need to be addressed to validate the findings. Mass spectrometric methods in combination with different separation techniques such as gel electrophoresis, chromatographic affinities have proven advantageous for initial studies. However, the technology still needs to be enhanced for larger scale proteomic studies in order to be used as a tool in clinical proteomics. In addition to the technological advances, global standardization procedures for sample collection, planning, execution, and validation are immediate concerns. Such steps will help achieve the ultimate goal of capturing critical information regarding a disease in one diagnostic step.

Most of earlier urinary and renal proteomics focused on expression proteomics with only a few on functional analyses. In the future, functional proteomics along with bioinformatics will be useful in identifying the proteins and their role in biology and physiology of kidneys. The future will move towards integration of other areas such as genomics, transcriptomics, and metabolomics to extract vast amounts of information and achieve the ultimate goal of personalized medicine.

Despite the progress in biomarker discovery, the contribution of urinary proteomics to the understanding of disease is modest due to difficulty of biomarker sequence identification and translation to immune-based assays. Our understanding of the human urinary proteome is incomplete with respect to its overall composition, dynamics, and identity of components that vary based on physiologic state and disease.

\section{Disclosure}

The authors report no conflicts of interest in this work.

\section{References}

1. Wilkins MR, Sanchez JC, Gooley AA, et al. Progress with proteome projects: why all proteins expressed by a genome should be identified and how to do it. Biotechnol Genet Eng Rev. 1996;13: $19-50$.

2. O'Farrell PH. High resolution two-dimensional electrophoresis of proteins. J Biol Chem. 1975;250:4007-4021.

3. Klose J. Protein mapping by combined isoelectric focusing and electrophoresis of mouse tissues. Humangenetik. 1975;26:231-243.

4. Michael SG, Francesco A, Edmond O. Diagnostic potential of urine proteome: a broken mirror of renal diseases. J Am Soc Nephrol. 2007; 18: 2233-2239.

5. Irena D, Pesic I, Ljubinka JV. Urinary and tissue proteomics of urothelial cancer. Acta Fac Med Naiss. 2008;25(2):75-80.

6. Zhou H, Yuen PS, Pisitkun T, et al. Collection, storage, preservation, and normalization of human urinary exosomes for biomarker discovery. Kidney Int. 2006;69:1471-1476.

7. Spahr CS, Davis MT, McGinley MD, et al. Towards defining the urinary proteome using liquid chromatography-tandem mass spectrometry. I. Profiling an unfractionated tryptic digest. Proteomics. 2001;1: 93-107.
8. Adachi J, Kumar C, Zhang Y, Olsen JV, Mann M. The human urinary proteome contains more than 1500 proteins, including a large proportion of membrane proteins. Genome Biol. 2006;7:R80.

9. Decramer S, Gonzalez de PA, Breuil B, et al. Urine in clinical proteomics. Mol Cell Proteomics. 2008;7:1850-1862.

10. Thongboonkerd V. Urinary proteomics: towards biomarker discovery, diagnostics and prognostics. Mol Biosyst. 2008;4:810-815.

11. Oetting WS, Rogers TB, Krick TP, Matas AJ, Ibrahim HN. Urinary beta2-microglobulin is associated with acute renal allograft rejection. Am J Kidney Dis. 2006;47:898-904.

12. Berger RP, Kochanek PM. Urinary S100B concentrations are increased after brain injury in children: a preliminary study. Pediatr Crit Care Med. 2006;7:557-561.

13. Vestergaard P, Leverett R. Constancy of urinary creatinine excretion. J Lab Clin Med. 1958;51:211-218.

14. Schiffer E, Mischak H, Novak J. High resolution proteome/peptidome analysis of body fluids by capillary electrophoresis coupled with MS. Proteomics. 2006;6:5615-5627.

15. Theodorescu D, Wittke S, Ross MM, et al. Discovery and validation of new protein biomarkers for urothelial cancer: a prospective analysis. Lancet Oncol. 2006;7:230-240.

16. Thongboonkerd V. Proteomics in nephrology: current status and future directions. Am J Nephrol. 2004;24:360-378.

17. Thongboonkerd V, Malasit P. Renal and urinary proteomics: current applications and challenges. Proteomics. 2005;5:1033-1042.

18. Hewitt SM, Dear J, Star RA. Discovery of protein biomarkers for renal diseases. J Am Soc Nephrol. 2005;15:1677-1689.

19. Free AH, Rupe CO, Metzler I. Studies with a new colorimetric test for proteinuria. Clin Chem. 1957;3:716-727.

20. McElderry LA, Tarbit IF, Cassells-Smith AJ. Six methods for urinary protein compared. Clin Chem. 1982;28:356-360.

21. Ginsberg JM, Chang BS, Matarese RA, Garella S. Use of single voided urine samples to estimate quantitative proteinuria. N Engl J Med. 1983; 309:1543-1546.

22. Gorg A, Weiss W, Dunn MJ. Current two-dimensional electrophoresis technology for proteomics. Proteomics. 2004;4:3665-3685.

23. Burnette WN. "Western blotting": electrophoretic transfer of proteins from sodium dodecyl sulfate-polyacrylamide gels to unmodified nitrocellulose and radiographic detection with antibody and radioiodinated protein A. Anal Biochem. 1981;112:195-203.

24. Aebersold R, Mann M. Mass spectrometry-based proteomics. Nature. 2003;422:198-207.

25. Thongboonkerd V. Recent progress in urinary proteomics. Proteomics Clin Appl. 2007;1:780-791.

26. Fliser D, Novak J, Thongboonkerd V, et al. Advances in urinary proteome analysis and biomarker discovery. J Am Soc Nephrol. 2007; 18:1057-1071.

27. Zürbig P, Renfrow MB, Schiffer E, et al. Biomarker discovery by CE-MS enables sequence analysis via MS/MS with platform-independent separation. Electrophoresis. 2006;27:2111-2125.

28. Pisitkun T, Shen RF, Knepper MA. Identification and proteomic profiling of exosomes in human urine. Proc Natl Acad Sci US A. 2004; 101:13368-13373.

29. Sun W, Li F, Wu S, et al. Human urine proteome analysis by three separation approaches. Proteomics. 2005;5:4994-5001.

30. Wang L, Li F, Sun W, et al. Concanavalin A captured glycoproteins in healthy human urine. Mol Cell Proteomics. 2006;5:560-562.

31. Delahunty CM, Yates JR. MudPIT: multidimensional protein identification technology. Biotechniques. 2007;43:563-567.

32. Castagna A, Cecconi D, Sennels L, et al. Exploring the hidden human urinary proteome via ligand library beads. J Proteome Res. 2005;4: 1917-1930.

33. Harald M, Joshua JC, Jan N, et al. Capillary electrophoresis-mass spectrometry as a powerful tool in biomarker discovery and clinical diagnosis: an update of recent developments. Mass Spectrom Rev. 2009; 28(5):703-724. 
34. Jochen M, Joost PS, Harald M. Capillary electrophoresis-mass spectrometry in urinary proteome analysis: current applications and future developments. Anal Bioanal Chem. 2009;393:1431-1442.

35. Dolnik V. Capillary electrophoresis of proteins 2005-2007. Electrophoresis. 2008;29:143-156.

36. Kasicka V. Recent developments in CE and CEC of peptides. Electrophoresis. 2008;29:179-206.

37. Clarke W, Silverman BC, Zhang Z, Chan DW, Klein AS, Molmenti EP. Characterization of renal allograft rejection by urinary proteomic analysis. Ann Surg. 2003;237:660-664.

38. Dare TO, Davies HA, Turton JA, Lomas L, Williams TC, York MJ. Application of surface-enhanced laser desorption/ionization technology to the detection and identification of urinary parvalbumin-alpha: a biomarker of compound-induced skeletal muscle toxicity in the rat. Electrophoresis. 2002;23:3241-3251.

39. Cretich M, Damin F, Pirri G, Chiari M. Protein and peptide arrays: recent trends and new directions. Biomol Eng. 2006;23:77-88.

40. Barratt J, Feehally J. IgA nephropathy. J Am Soc Nephrol. 2005;16: 2088-2097.

41. Neuhoff N, Kaiser T, Wittke S, et al. Mass spectrometry for the detection of differentially expressed proteins: a comparison of surfaceenhanced laser desorption/ionization and capillary electrophoresis/ mass spectrometry. Rapid Commun Mass Spectrom. 2004;18: 149-156.

42. Rocchetti MT, Centra M, Papale M, et al. Urine protein profile of IgA nephropathy patients may predict the response to ACE-inhibitor therapy. Proteomics. 2008;8:206-216.

43. Caramori ML, Fioretto P, Mauer M. The need for early predictors of diabetic nephropathy risk: is albumin excretion rate sufficient? Diabetes. 2000;49:1399-1408.

44. Meier M, Kaiser T, Herrmann A, et al. Identification of urinary protein pattern in type 1 diabetic adolescents with early diabetic nephropathy by a novel combined proteome analysis. J Diabetes Complicat. 2005; 19:223-232.

45. Rossing K, Mischak H, Rossing P, Schanstra JP, Wiseman A, Maahs DM. The urinary proteome in diabetes and diabetes-associated complications: new ways to assess disease progression and evaluate therapy. Proteomics Clin Appl. 2008;2:997-1007.

46. Sharma K, Lee S, Han S, et al. Two-dimensional fluorescence difference gel electrophoresis analysis of the urine proteome in human diabetic nephropathy. Proteomics. 2005;5:2648-2655.

47. Dihazi H, Muller GA, Lindner S, et al. Characterization of diabetic nephropathy by urinary proteomic analysis: identification of a processed ubiquitin form as a differentially excreted protein in diabetic nephropathy patients. Clin Chem. 2007;53:1636-1645.

48. Wittke S, Haubitz M, Walden M, et al. Detection of acute tubule interstitial rejection by proteomic analysis of urinary samples in renal transplant recipients. Am J Transplant. 2005;5:2479-2488.

49. O'Riordan E, Orlova TN, Podust VN, et al. Characterization of urinary peptide biomarkers of acute rejection in renal allografts. Am J Transplant. 2007; 7:930-940.

50. Quintana LF, Solé-Gonzalez A, Kalko SG, et al. Urine proteomics to detect biomarkers for chronic allograft dysfunction. J Am Soc Nephrol. 2009;20(2):428-435.

51. Uchino S, Kellum JA, Bellomo R, et al. Acute renal failure in critically ill patients: a multinational, multicenter study. JAMA. 2005;294: 813-818.

52. Lameire N, van Biesen W, Vanholder R. Acute renal failure. Lancet 2005;365:417-430.

53. Lefler DM, Pafford RG, Black NA, Raymond JR, Arthur JM. Identification of proteins in slow continuous ultrafiltrate by reversedphase chromatography and proteomics. J Proteome Res. 2004;3(6): 1254-1260.

54. Molls RR, Savransky V, Liu M, et al. Keratinocyte-derived chemokine is an early biomarker of ischemic acute kidney injury. Am J Physiol Renal Physiol. 2006;290:F1187-F1193.
55. Zhou H, Pisitkun T, Aponte A, et al. Exosomal fetuin-A identified by proteomics: a novel urinary biomarker for detecting acute kidney injury. Kidney Int. 2006;70:1847-1857.

56. Rogers MA, Clarke P, Noble J, et al. Proteomic profiling of urinary proteins in renal cancer by surface enhanced laser desorption ionization and neural-network analysis: identification of key issues affecting potential clinical utility. Cancer Res. 2003;63:6971-6983.

57. Rehman I, Azzouzi AR, Catto JW, et al. Proteomic analysis of voided urine after prostatic massage from patients with prostate cancer: a pilot study. Urology. 2004;64:1238-1243.

58. Kageyama $\mathrm{S}$, Isono $\mathrm{T}$, Iwaki $\mathrm{H}$, et al. Identification by proteomic analysis of calreticulin as a marker for bladder cancer and evaluation of the diagnostic accuracy of its detection in urine. Clin Chem. 2004; 50:857-866.

59. Iwaki H, Kageyama S, Isono T, et al. Diagnostic potential in bladder cancer of a panel of tumor markers (calreticulin, gamma-synuclein, and catechol-o-methyltransferase) identified by proteomic analysis. Cancer Sci. 2004;95:955-961.

60. Ye B, Skates S, Mok SC, et al. Proteomic-based discovery and characterization of glycosylated eosinophil-derived neurotoxin and $\mathrm{COOH}$-terminal osteopontin fragments for ovarian cancer in urine. Clin Cancer Res. 2006;12:432-441.

61. Theodorescu D, Fliser D, Wittke S, et al. Pilot study of capillary electrophoresis coupled to mass spectrometry as a tool to define potential prostate cancer biomarkers in urine. Electrophoresis. 2005;26: 2797-2808.

62. Theodorescu D, Eric Schiffer E, Bauer HW, et al. Discovery and validation of urinary biomarkers for prostate cancer. Proteomics Clin Appl. 2008;2:997-1007.

63. Orenes-Pinero E, Corton M, Gonzalez-Peramato P, et al. Searching urinary tumor markers for bladder cancer using a two-dimensional differential gel electrophoresis (2D-DIGE) approach. J Proteome Res. 2007;6:4440-4448.

64. Vlahou A, Schellhammer PF, Mendrinos S, et al. Development of a novel proteomic approach for the detection of transitional cell carcinoma of the bladder in urine. Am J Pathol. 2001;158:1491-1502.

65. Welton JL, Khanna S, Giles PJ, et al. Proteomics analysis of bladder cancer exosomes. Mol Cell Proteomics. 2010;9:1324-1338.

66. Weissinger EM, Schiffer E, Hertenstein B, et al. Proteomic patterns predict acute graft-versus-host disease after allogeneic hematopoietic stem cell transplantation. Blood. 2007;109:5511-5519.

67. Polotsky VY, O'Donnell CP. Genomics of sleep-disordered breathing. Proc Am Thorac Soc. 2007;4:121-126.

68. Chambers AF, Vanderhyden BC. Ovarian cancer biomarkers in urine. Clin Cancer Res. 2006;12:323-327.

69. Tantipaiboonwong P, Sinchaikul S, Sriyam S, et al. Different techniques for urinary protein analysis of normal and lung cancer patients. Proteomics. 2005;5:1140-1149.

70. Zimmerli LU, Schiffer E, Zurbig P, et al. Urinary proteomic biomarkers in coronary artery disease. Mol Cell Proteomics. 2008;7:290-298.

71. Kalela A, Koivu TA, Sisto T, et al. Serum matrix metalloproteinase-9 concentration in angiographically assessed coronary artery disease. Scand J Clin Lab Invest. 2002;62:337-342.

72. Noji Y, Kajinami K, Kawashiri MA, et al. Circulating matrix metalloproteinases and their inhibitors in premature coronary atherosclerosis. Clin Chem Lab Med. 2001;39:380-384.

73. Tayebjee MH, Tan KT, MacFadyen RJ, Lip GY. Abnormal circulating levels of metalloprotease 9 and its tissue inhibitor 1 in angiographically proven peripheral arterial disease: relationship to disease severity. J Intern Med. 2005;257:110-116.

74. Ingegno MD, Money SR, Thelmo W, et al. Progesterone receptors in the human heart and great vessels. Lab Invest. 1988;59:353-356.

75. von Zur Muhlen C, Schiffer E, Zuerbig P, et al. Evaluation of urine proteome pattern analysis for its potential to reflect coronary artery atherosclerosis in symptomatic patients. J Proteome Res. 2009;8: $335-345$. 
76. Snell-Burgeon DM, Maahs LG, Ogden GL, et al. Evaluation of urinary biomarkers for coronary artery disease, diabetes, and diabetic kidney disease. Diabetes Technol Ther. 2009;11:1-9.

77. Thongboonkerd V. Current status of renal and urinary proteomics: ready for routine clinical application? Nephrol Dial Transplant. 2010; 25:11-16.

78. Yamamoto T, Langham RG, Ronco P, et al. Towards standard protocols and guidelines for urine proteomics: a report on the Human Kidney and Urine Proteome Project (HKUPP) Symposium; 2007 Oct 6; Seoul, Korea and Workshop; 2007 Nov 1; San Francisco, CA. Proteomics. 2008;8:2156-2159.
79. Vlahou A, Schanstra J, Frokiaer J, et al. Establishment of a European network for urine and kidney proteomics. J Proteomics. 2008;71: 490-492.

80. Thongboonkerd V. Practical points in urinary proteomics. J Proteome Res. 2007;6:3881-3890.

\section{Publish your work in this journal}

International Journal of High Throughput Screening is an international, peer-reviewed, open access journal publishing original research, reports, editorials, reviews and commentaries dedicated to all aspects of high throughput screening, especially related to drug discovery and associated areas of biology and chemistry. The manuscript management sys-

tem is completely online and includes a very quick and fair peer-review system. Visit http://www.dovepress.com/testimonials.php to read real quotes from published authors.

\footnotetext{
Submit your manuscript here: http://www.dovepress.com/international-journal-of-high-throughput-screening-journal
} 